\title{
A PRÁTICA DA ESCRITA E DA REESCRITA ORIENTADA NO PROCESSO DE SIGNIFICAÇÃO CONCEITUAL EM AULAS DE QUÍMICA
}

\author{
Judite Scherer Wenzel ${ }^{*}$
}

Otavio Aloisio Maldaner**

RESUMO: Apresenta-se um recorte de pesquisa de doutoramento que teve como objetivo principal propiciar a estudantes de curso de licenciatura em Ciências o uso e a significação da linguagem química mediante a escrita e a reescrita em processo de orientação qualificada. Para a produção de dados, foram utilizados princípios da análise textual discursiva segundo categorias de análise a priori resultados da análise dos textos dos estudantes e de orientação com atenção, em especial, para a interação discursiva e a possibilidade de apropriação conceitual e evolução conceitual. Os resultados permitem afirmar que o uso da linguagem química pelos estudantes em espaços orientados possibilitou avanços na significação conceitual em química, com diferentes níveis de generalização.

Palavras-chave: Aprendizagem química. Interação discursiva. Escrita e reescrita.

\section{LA PRÁCTICA DE LA ESCRITA Y REESCRITA ORIENTADA EN EL PROCESO DE SIGNIFICACIÓN CONCEPTUAL EN CLASES DE QUÍMICA}

RESUMEN: Presentamos un recorte de investigación de doctoramiento que tuvo como objetivo principal propiciar a estudiantes de licenciatura en Ciencias el uso y la significación del lenguaje químico mediante la escrita y la reescrita en proceso de orientación calificada. Para producción de datos, fueron utilizados principios del análisis textual discursivo segundo categorías de análisis a priori y elaboración de categorías emergentes. La discusión contempla los resultados del análisis de los textos de los estudiantes y de orientación con atención, en especial, para la interacción discursiva y la posibilidad de apropiación conceptual y evolución conceptual. Los resultados permiten afirmar que el uso del lenguaje químico por los estudiantes en espacios orientados posibilitó avances en la significación conceptual en química, con diferentes niveles de generalización.

Palabras clave: Aprendizaje químico. Interacción discursiva. Escrita y reescrita. e elaboração de categorias emergentes. A discussão contempla os

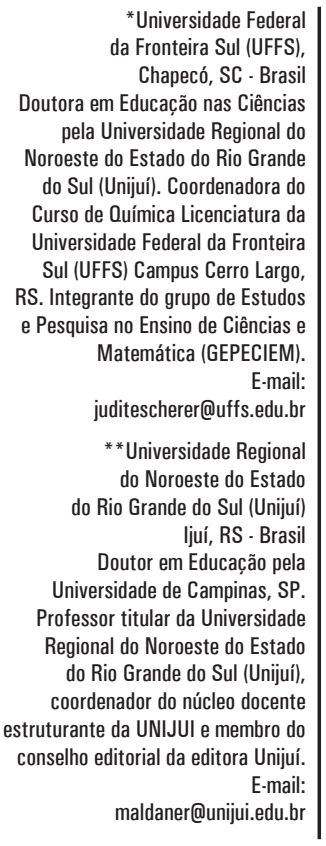

DOI - - http://dx.doi.org/10.1590/1983-21172016180206 
ORIENTED PRACTICE OF WRITING AND REWRITING AS A CONCEPTUAL MEANING PROCESS IN CHEMISTRY CLASSES

ABSTRACT: We present a Doctoral Degree Research clipping that had, as main goals, to offer the use and the meaning of Chemistry language Science Undergraduate Students, through writing and rewriting in qualified guidance process. To produce data, textual content analysis principles were used a priori and we elaborated emerging categories in the process. The discussion considers the results of the students' textual analysis and guidance with attention in particular, especially discursive interaction and the possibility of conceptual appropriation and conceptual evolution. The results can state that Chemistry language use by the students in guided places enabled advances in the conceptual meaning in chemistry with different levels of generalization.

Keywords: Chemistry learning. Discursive interaction. Writing and rewriting. 


\section{INTRODUÇÃO}

O presente artigo ${ }^{1}$ contempla parte dos resultados construídos na investigação de doutoramento (WENZEL, 2013) que teve como foco indícios da evolução conceitual em química em processo de escrita e reescrita orientada no Componente Curricular de Química Introdutória de um curso de graduação. A origem da problemática da pesquisa esteve ancorada na experiência dos autores como professores de química, mais especificamente pelo fato de que os estudantes, ao serem solicitados a escrever sobre um fenômeno, um experimento ou uma leitura, nas suas respostas, não avançavam na construção de significados químicos e não conseguiam, mesmo no fim do semestre, fazer as relações mínimas e necessárias entre conceitos químicos. Com isso, decorrem os questionamentos iniciais da pesquisa: "o que fazer para possibilitar o início da formação do pensamento químico dos estudantes?”.

Considerando-se a relação pensamento/linguagem e tendo-se como base teórica o referencial histórico-cultural, assumiu-se, na prática da pesquisa realizada, que a linguagem é instrumento de comunicação e interação social, convertendose gradativamente em processo de constituição do humano específico de cada indivíduo. No ensino de química e de qualquer outra ciência, é o uso qualificado da sua linguagem na interação professor/estudantes que possibilita a estes a significação e a apropriação do conhecimento específico, tornando-os capazes de pensar o mundo da vida na forma da ciência. Com isso e a fim de responderem ao questionamento inicial, os pesquisadores elaboraram e acompanharam uma prática de ensino ${ }^{2}$ que, com diferentes instrumentos pedagógicos ${ }^{3}$, possibilitou aos estudantes o uso da linguagem química por meio da escrita e da reescrita de textos num processo orientado pedagogicamente.

A escolha de tal prática esteve ancorada na defesa teórica da importância de o estudante fazer uso da linguagem química para, assim, permitir a sua apropriação e a evolução do significado conceitual em química, bem como oportunizar a formação do pensamento químico. E, neste artigo, a atenção está voltada para as interações discursivas estabelecidas no processo de reescrita, orientado como forma de qualificar a significação conceitual em química pelos estudantes.

Parte-se do entendimento de que, no âmbito de uma aula de química, a linguagem utilizada pelo professor consiste na Linguagem Científica Escolar (LCE), que contempla diferentes gêneros discursivos: discurso científico, divulgação científica e discurso pedagógico. Ambos apresentam especificidades que precisam ser apreendidas pelos estudantes para tornar possível a construção do conhecimento escolar-científico. Os gêneros discursivos caracterizam-se como enunciados estáveis que apresentam conteúdos temáticos, estilo próprio e, também, uma construção composicional específica (BAKHTIN, 2010). Ou seja, entende-se que a linguagem de um gênero discursivo é histórica e concreta e, por isso, ocorre no âmbito de interações sociais de uma determinada esfera social, como, por exemplo, a sala de aula, pois essa apresenta objetivos, direções e público específico: os estudantes.

Assim, nas aulas de química, o discurso estabelecido caracteriza-se por uma linguagem bastante específica, que vai ao encontro dos diferentes discursos 
cotidianos trazidos pelos estudantes, e a interação discursiva que ocorre no processo pedagógico pode propiciar maior consciência sobre um mesmo fenômeno em circulação nesse encontro de linguagens. Para tanto, são imprescindíveis a atenção do professor ao discurso que acontece em sala de aula e a constante vigilância sobre os sentidos que estão sendo produzidos. Compreende-se, com base em Vigotski (2000), que o sentido dado à palavra/conceito é atribuído pelo sujeito na busca da compreensão e da interpretação de mundo, de acordo com suas capacidades cognitivas, também vinculadas ao contexto do sujeito e de suas vivências anteriores. Diz Vigotski (2000, p. 465) que "o sentido é sempre uma formação dinâmica, fluida, complexa, que tem várias zonas de estabilidade variada”.

Nessa direção, em sala de aula, instaura-se um processo interativo que precisa, pelo posicionamento do professor, (re)direcionar os sentidos atribuídos inicialmente pelos estudantes, buscando aproximá-los dos significados químicos aceitos. De acordo com Vigotski (2000, p. 465), entende-se o significado como sendo uma compreensão historicamente construída, "uma pedra no edifício dos sentidos", sendo, portanto, mais estável do que os sentidos, que são sempre dos sujeitos em processo interativo. No contexto de uma aula de química, as relações entre sentido e significado constituem as diferentes interações discursivas estabelecidas, o que implica "uma dialética de forças que compõem a significação da palavra, que não deve ser ignorada no estudo de qualquer dos processos humanos" (CRUZ; GÓES, 2006, p. 9), daí a importância de se investigarem os processos de interações discursivas estabelecidas em sala de aula.

E, assim, considerando-se a importância de espaços pedagógicos que potencializem a interação discursiva favorável em sala de aula, faz-se a defesa da inserção da escrita e da reescrita orientada nas aulas de química. Vincula-se essa defesa ao entendimento de Vigotski (2000) de que, se algo não tem significado, não é possível falar ou escrever sobre ele. Ao estudante somente será possível pensar sobre e explicar de maneira coerente um determinado fenômeno químico, fazendo uso adequado das palavras específicas da química, quando essas fizerem sentido para ele dentro do contexto do conhecimento químico. A simples repetição de palavras próprias da química produz a memorização mecânica, sem significado e sem formar relações entre os conceitos. Portanto, é aprendizagem mecânica, o contrário de aprendizagem significativa. Ao se internalizarem significados através do esforço da escrita e da reescrita, a escolha das palavras para produzir um pensamento químico em determinada situação será consciente e com base nos modelos teóricos da química. Nas palavras de Vigotski (2000, p. 479), "o significado medeia o pensamento em sua caminhada rumo à expressão verbal".

No presente trabalho, a interação discursiva que foi analisada ocorreu num processo de escrita e de reescrita orientado. Justifica-se a escolha pela prática da escrita, em detrimento da fala e da leitura, com o entendimento de Vigotski (2000) de que o escrever difere do falar por requerer um alto grau de abstração. A escrita é considerada importante ferramenta para estruturar o pensamento e a lógica argumentativa, pois exige maior organização cognitiva do que a fala, na qual os interlocutores se comunicam utilizando recursos como gestos, diferentes tons expressivos e outros. Entende-se que a compreensão na escrita somente é possível pelo conjunto de palavras e de combinações usadas bem articuladas e estruturadas, 
o que requer um maior nível de generalização e abstração.

Com base numa revisão bibliográfica realizada (WENZEL, MALDANER 2014), foi possível evidenciar lacunas na discussão referente à escrita nos cursos de graduação em química. Observou-se que o uso de tal prática, na sua maioria, restringese a um processo mecânico que pouco contribui efetivamente para o aprendizado. Preocupou-se mais com a apropriação dos modos de escrita da linguagem específica do que com a significação conceitual em química no processo de escrita.

Em suma, a temática central deste artigo está ancorada no entendimento de que, para aprender química, como também em outros campos do conhecimento escolar, é preciso estabelecer interações discursivas favoráveis em sala de aula. Essas implicam a conscientização do professor sobre a linguagem a ser utilizada e, em contrapartida, a necessidade de o estudante assumir o estudo como atividade principal em seu processo de formação, possibilitando a apropriação e a significação conceituais, com a qualidade esperada e requerida.

Segue a discussão de alguns dos resultados construídos com base em análises realizadas nos textos dos estudantes e nas orientações dadas pela professora, com atenção para o processo de interação discursiva. Os resultados foram obtidos mediante a metodologia da Análise Textual Discursiva (ATD) (MORAES; GALIAZZI, 2011), sendo que o corpus da análise foi constituído a partir dos textos escritos e reescritos pelos estudantes e dos textos de orientação. Na próxima seção, serão apresentados alguns aspectos tanto da metodologia de pesquisa como da prática de ensino vivenciada.

\section{OSCAMINHOS METODOLÓGICOS PERCORRIDOSE O CONTEXTO DE ENSINO VIVENCIADO}

A prática de ensino à qual se refere o presente artigo ocorreu, ao longo de um semestre, nas aulas ministradas no componente curricular Química $\mathrm{I}^{4}$ da primeira fase do curso, cuja oferta é no turno da noite. Os estudantes que participaram da investigação ainda não apresentavam vínculos com projetos de pesquisa e, em sua grande maioria, não tinham dedicação exclusiva aos estudos. A escolha das aulas de química I se deve ao fato de um dos autores do artigo atuar como professor desse componente curricular e ter optado por transformar suas aulas em momentos de pesquisa. Assim, na primeira aula de química I, todos os alunos foram convidados a participar como sujeitos da pesquisa, depois de terem conhecido a temática da pesquisa e recebido o Termo de Consentimento Livre e Esclarecido (TCLE).

$\mathrm{Na}$ expectativa de proporcionarem espaços formativos para a evolução na significação conceitual com o uso da linguagem química, os estudantes, no decorrer das aulas, fizeram uso de diferentes instrumentos pedagógicos - caderno de anotações; provas descritivas; reescrita orientada das provas e elaboração de mapas conceituais - que possibilitaram a prática da escrita e da reescrita. Os textos produzidos pelos estudantes, após terem passado por critérios de seleção, constituíram o corpus da pesquisa e também foram objeto de avaliação do componente curricular. Com isso, independentemente de terem participado ou não da pesquisa, todos os alunos tiveram os seus corrigidos e avaliados, e as suas reescritas orientadas.

Cada um dos instrumentos pedagógicos apresentou particularidades de aplicação e de organização metodológicas. Considerando-se que os resultados 
exibidos neste artigo decorrem da análise das escritas assinaladas no caderno de anotações, é importante explicitá-lo. Não se trata daquele caderno costumeiramente utilizado em aula para fazer anotações. Inicialmente, ele tinha outra finalidade: nele os estudantes respondiam questões formuladas nas aulas, escreviam sobre as aulas experimentais e/ou sobre leituras feitas. A escrita no caderno de anotações perpassou todo o semestre. Ao todo, foram cinco textos entregues para a leitura e a análise da professora, que, posteriormente, fazia orientações por escrito para cada um dos alunos a fim de que eles procedessem à reescrita. As orientações se davam na forma de textos escritos ou de símbolos, que indicavam as limitações conceituais nas escritas dos estudantes. A professora oferecia pistas que visavam auxiliá-los, indicando os necessários (re)direcionamentos da escrita ou sua ampliação. Como a maioria das escritas no caderno de anotações não foi realizada em aula, os alunos tinham acesso a um número maior de materiais de consulta.

Quanto à metodologia empregada para as orientações, foram feitos comentários descritivos em cada um dos cadernos, para cada uma das questões respondidas, e eles consistiam em apontamentos sobre limitações conceituais percebidas nas respostas, em indicativos de caminhos teóricos para serem pensados ou ainda em perguntas que deveriam ser respondidas. Na primeira correção, alguns dos comentários ultrapassavam uma página. Muitos deles eram semelhantes, pois os estudantes apresentavam em seus textos erros parecidos. Esse fator aliado ao montante de trabalho levou à (re)avaliação da metodologia, e a alternativa encontrada foi elaborar símbolos para nortear a reescrita. Assim, na segunda correção foi utilizada uma folha com símbolos que padronizavam a indicação para a reescrita, o que facilitou o trabalho de orientação da professora. Todavia, em correções posteriores, percebendo limitações de alguns estudantes quanto à interpretação dos símbolos, a professora retomou o método de inserir comentários. Assim, em determinadas orientações, fez-se uso de uma orientação mista, contemplando-se a escrita de um comentário e o emprego de um símbolo.

No fim do semestre, havia 59 cadernos, os quais perpassaram todas as entregas de reescrita. No contexto geral da pesquisa de doutoramento, o critério utilizado para a seleção dos cadernos - foram sete - considerou os que apresentaram mais de duas reescritas para a resposta da primeira questão ${ }^{5}$, encaminhada após a primeira aula de química I, depois da leitura do artigo "Água: um líquido vital". A opção por essa questão se justifica tanto por ela possibilitar um número maior de reescritas quanto por sua temática ser ampla, contemplando a ementa do componente curricular química I. Aos estudantes que se envolveram no processo da escrita e da reescrita, que ampliaram as discussões no decorrer do diálogo, foram permitidas quatro reescritas.

Para o presente artigo, a fim de compreendermos a interação discursiva estabelecida no processo de reescrita orientado para essa primeira questão, selecionamos excertos dos diálogos mantidos por dois estudantes (F e G), os quais foram escolhidos por terem apresentado indícios de apropriação e evolução conceituais.

Em relação ao procedimento analítico metodológico adotado, foram utilizados aportes da Análise Textual Discursiva (ATD). Ao se iniciar a análise das respostas dos estudantes, direcionou-se a atenção para duas categorias estabelecidas a priori, a saber: a apropriação conceitual, compreendida como o processo em que 
o estudante, em sua escrita, utiliza termos específicos da Linguagem Científica Escolar (LCE), mas sem indiciar uma significação química para eles, e a evolução conceitual, em que o aluno, no uso dos termos específicos, relaciona conceitos para explicar determinado fenômeno. As partes dos textos que indiciavam aspectos dessas categorias foram separadas em unidades de significados. Porém, dentro dos textos, essas partes evidenciaram outras unidades de significados. Por isso, foram elaboradas as seguintes categorias emergentes: Especificidades da LCE; Interação Discursiva e Constituição Docente. Dessas, no presente artigo, foram privilegiados os elementos relativos à Interação Discursiva (ID), a qual, por sua vez, está diretamente relacionada às categorias a priori.

A interação discursiva é entendida, no âmbito do diálogo estabelecido, pelo processo de orientação na escrita e na reescrita, como um movimento que buscou a significação conceitual. Assim, compreendemos a interação discursiva no contexto pedagógico como um movimento no qual a palavra do professor vai ao encontro das que os estudantes já apresentam e vice-versa. Esse processo discursivo na significação conceitual corrobora Fontana (2005, p. 28), que, com base em Bakhtin, afirma que "o processo de elaboração conceitual emerge como processo de articulação, pelo confronto, de muitas vozes social e historicamente definidas em condição de interação - compreensão/expressão - determinadas".

Para se qualificar a compreensão da interação discursiva, segue uma discussão sobre os diálogos no processo de escrita e reescrita orientadas entre os estudantes F e G, que apresentaram indícios de apropriação conceitual e de evolução conceitual em diferentes momentos do processo interativo vivenciado.

\section{RESULTADOSEDISCUSSÕES: ATENÇÃOPARA AINTERAÇÃODISCURSIVAESTABELECIDA}

De início, reitera-se que a importância da interação discursiva em sala de aula vincula-se ao entendimento de que a significação conceitual está relacionada com as condições de interações estabelecidas e suas expressões. Com apoio em Fontana (2005, p. 26), que diz que a significação conceitual "é o efeito da interlocução entre os interlocutores", reafirma-se a relevância de o professor atentar para a interação discursiva estabelecida em sala de aula e de se conscientizar sobre ela. Além de propiciar espaços de fala e/ou de escrita, ele precisa aprender a ouvir o que o aluno diz em sala de aula para mediar qualificadamente o seu posicionamento. Considera-se que a interação discursiva favorável é condição para oportunizar avanços na significação conceitual dos estudantes.

Nessa direção, o processo de reescrita orientada objetivou avanços do entendimento sobre química por parte dos alunos. Além disso, possibilitando ao estudante ler novamente seu texto, agora à luz das orientações, esse processo visou à tomada de consciência e à evolução do significado conceitual na disciplina.

Todo o trabalho de escrita e reescrita se caracterizou como um diálogo entre as orientações encaminhadas e os textos dos estudantes, com vistas a ampliar as compreensões dos sujeitos envolvidos.

Essa prática vivenciada vincula-se ao entendimento de Vigotski (2000, p. 329) de que "em colaboração a criança sempre pode fazer mais do que sozinha". O mesmo autor (2000) ressalta que, com a ajuda do outro, é possível avançar 
dentro dos seus limites de desenvolvimento e de suas potencialidades intelectuais. Com isso, assumiu-se o aprendizado como um processo colaborativo, de relação assimétrica, em que o estudante aprende com alguém mais capaz, com as orientações da professora.

Ainda com base em Bakhtin (2010), entende-se que a interação discursiva estabelecida no processo pedagógico é uma enunciação, uma vez que apresenta um direcionamento, um público específico e objetivos peculiares. Em outras palavras, a interação discursiva retrata uma relação entre o discurso exterior e o interior, num processo que uma pessoa busca a compreensão da palavra do outro até ela se tornar palavra própria. Segundo Bakhtin (2006, p. 127),

compreender a enunciação de outrem significa orientar-se em relação a ela, encontrar o seu lugar adequado no contexto correspondente. A cada palavra da enunciação que estamos em processo de compreender, fazemos corresponder uma série de palavras nossas, formando uma réplica. Quanto mais numerosas e substanciais forem, mais profunda e real é a nossa compreensão.

Essa atitude responsiva precisa ser conquistada em sala de aula, e, para isso, é importante a inserção de metodologias que favoreçam o uso qualificado da linguagem nesse ambiente. Aqui, resumidamente, pode-se dizer que a meta foi desafiar os estudantes e estimulá-los a seguirem outro caminho na produção do pensamento, bem como possibilitar a tomada de consciência das limitações nos significados conceituais em química, de modo a ampliá-los. Ou seja, o processo de orientação objetivou uma interação discursiva favorável entre a professora e os estudantes.

É importante especificar que, no diálogo instituído, a escrita não era uma prática livre; ela era direcionada, devendo o estudante, em suas respostas, apresentar uma linguagem específica e sua argumentação conter significados coerentes com os conhecimentos químicos formados. Tal direcionamento se justifica em função do contexto (escolar/acadêmico) em que a interação foi produzida.

Com o intuito de qualificarmos a discussão referente ao processo de interação discursiva, trazemos alguns diálogos do processo de escrita e de reescrita. É preciso atentar para as orientações encaminhadas pela professora e para as palavras usadas pelos estudantes. O diálogo consiste no processo de resposta e orientação para a reescrita da primeira questão (apresentada na nota de rodapé 5), assinalada no caderno de anotações. Iniciamos com o diálogo estabelecido com o estudante F, que, em sua resposta, apenas contemplou aspectos relacionados à propriedade da água:

uma das propriedades mais importantes da água líquida é a sua capacidade de dissolver substâncias iônicas para formar soluções aquosas. Densidade - a água sólida é menos densa que o líquido por esta razãa o gelo boia sobre a água líquida o que protege os peixes e plantas de lagos e rios no inverno. Há outras propriedades da água que merecem destaque [...] (Caderno de anotações, estudante F, p. 1, 2012).

Continuando seu texto, o estudante $\mathrm{F}$ define tensão superficial e apresenta os valores da constante dielétrica, do calor de vaporização e do calor especifico da água, numa escrita apenas descritiva, uma cópia. Por essa razão, esse trecho não foi 
reproduzido neste espaço. De modo geral, a escrita do estudante não respondeu à pergunta, que solicitava a explicação da causa das propriedades peculiares da água. Assim, o comentário para orientar a reescrita foi o seguinte:

na resposta da primeira questão faltou você explicar as causas das propriedades da água que você citou. Como por exemplo, explicar porque substâncias polares e iônicas são soliveis em água. E ainda, explicar por que a água é liquida a temperatura ambiente, e ainda, porque o gelo é menos denso que a água líquida (Caderno de anotações, p. 7, 2012).

O comentário feito pela professora pretendeu fazer com que F pensasse na explicação química para fenômenos percebidos por ele no dia a dia, como, por exemplo, o gelo boiar sobre a água líquida, o óleo não ser solúvel em água e tantos outros que estão relacionados com as propriedades físico-químicas da água e que apenas serão compreendidos quando o conhecimento químico for significado pelo aluno. Acredita-se na necessidade de o estudante pensar sobre os fenômenos e de buscar uma explicação para as propriedades da água, as quais foram somente descritas por ele no primeiro momento. A iniciativa da professora de instigar o estudante a avançar em sua escrita coincide com a metodologia da pesquisa em sala de aula, que defende um processo de ensino que supere a condição de cópia e que possibilite ao aluno espaços para firmar seu posicionamento e reconstruir seus conhecimentos.

$\mathrm{Na}$ sua primeira reescrita, o estudante $\mathrm{F}$ escreveu sobre a polaridade da molécula de água e exemplificou a solubilidade de compostos polares e apolares em água, concluindo com uma referência à ligação hidrogênio:

\begin{abstract}
a molécula de água é polar (tem um polo positivo e um negativo). A água é um solvente universal, outras substâncias como moléculas polares são soliveis em água, enquanto as polares são insolíveis, por exemplo. água e óleo tem parte da molécula apolar, portanto não se mistura com água [...] o oxigênio de uma molécula atrai bidrogênios de outras moléculas de água, pois o negativo atrai o positivo - estabelecendo uma ligação chamada de ponte de hidrogênio, essa interação é a responsável pelas propriedades da água, em particular, pelo fato de a água ser líquida a temperatura ambiente (Cadernos de anotação, estudante F, p. 9, 2012).
\end{abstract}

Ao se analisar o movimento de escrita e reescrita do estudante $\mathrm{F}$, apesar de ele ser ainda incipiente, é possível perceber avanços na sua argumentação, uma vez que sua escrita passa de meramente descritiva, na qual reproduziu definições das propriedades da água de forma isolada, para algo mais argumentado, com o auxílio de exemplos do dia a dia, como o do fenômeno de solubilidade da água. Outro progresso feito por $\mathrm{F}$ em sua reescrita pôde ser percebido quando ele explicou os motivos de a água ser líquida na temperatura ambiente, justificando o fenômeno com as interações intermoleculares, ligações de hidrogênio. Tudo isso evidenciou avanços na significação. É importante que os estudantes percebam as relações entre a estrutura da matéria, as interações intermoleculares e as propriedades percebidas, como, por exemplo, o alto ponto de ebulição da água.

Dada essa resposta pelo aluno, a professora sublinhou os exemplos descritos e inseriu os símbolos DT (Rever/Ampliar a Discussão Teórica - faltou discutir o fenômeno, suas causas) e RI (Resposta Incompleta - reler o comentário feito anteriormente ou reler a questão, a pergunta, o problema) na tentativa de 
mostrar ao estudante que ele ainda não contemplou a causa da diferença da densidade da água líquida e da sólida, conforme solicitado anteriormente.

$\mathrm{Na}$ segunda reescrita, o estudante $\mathrm{F}$ avançou nas argumentações especificamente sobre a polaridade da água, fazendo uso de um vocabulário mais próximo da química. O emprego de palavras adequadas ao contexto é um caminho inicial e necessário no processo de significação conceitual.

A água com os ions de um sal, composto iônico, apresenta uma interação favorável, chamada de iondipolo e assim é capaz de formar soluções com alguns desses compostos [...] o oxigênio atrai os elétrons da ligacão muito mais fortemente que o bidrogênio devido a sua carga nuclear efetiva, levando uma carga parcial positiva nos átomos de bidrogênio e uma carga resultante negativa nos átomos de oxigênio. Isso e $\underline{\text { a }}$ geometria da molécula da água gera um momento dipolo. A atração elétrica devido a esse dipolo aproxima as moléculas de água, tornando difícil separá-las, e por consequência elevando o ponto de ebulição. Essa atração é conhecida como ligação de hidrogênio. Densidade é uma relação entre massa e volume. O aumento do volume da água líquida ocorre devido aos espaços vazios entre as moléculas de água ocasionados pela estrutura cristalina formada, pois no estado sólido cada molécula de água faz mais ligações de hidrogênio do que no estado líquido, tornando a estrutura mais rígida, mais organizada (Caderno de anotações, estudante F, p. 29-31, 2012, grifos nossos).

Nessa escrita, para se explicar a condição de solvente universal, percebese a utilização de termos específicos da química, como "carga nuclear efetiva", "atração elétrica", "carga resultante", "geometria da molécula", "momento dipolo" e "ligações hidrogênio". E essa explicação levou F a outras características inerentes às moléculas de água, como, por exemplo, “alto ponto de ebulição”. Tal movimento retrata a apropriação do discurso escolar, evidenciando aspectos dos discursos constituintes da LCE.

O estudante usou termos específicos da química (destacados no texto), que estão mais próximos do discurso científico, mas ele também se aproximou do discurso pedagógico, pois ele se preocupou em explicar o fenômeno de maneira didática, de modo que todos pudessem entender a mensagem transmitida. Isso pode ser percebido mais especificamente quando F escreveu "tornando difícil separá-las e por consequência”. Esses termos, na linguagem científica, não seriam empregados, já que um químico entenderia tal relação de forma direta. Entretanto, no âmbito escolar, é necessário fazer um discurso ampliando as explicações com o auxílio de adjetivos e de advérbios, já que o objetivo é possibilitar que o estudante identifique e compreenda os termos mais específicos da linguagem química. Daí, ficam novamente evidenciadas a multiplicidade de gêneros discursivos na sala de aula e a necessidade de sua apropriação e de sua significação pelos alunos no processo pedagógico vivenciado.

Segundo Bakhtin (2010), a palavra pode se apresentar em três aspectos: sendo neutra, sem pertencer a ninguém; sendo dos outros, quando apresenta a interpretação de outras pessoas, e sendo nossa, quando conseguimos operar numa situação determinada, como no contexto pedagógico. Numa aula de química, por exemplo, é importante que o estudante se aproprie de palavras específicas da área, com um significado mais próximo do contexto da química.

Analisando-se as diferentes relações conceituais estabelecidas no discurso 
de F, percebem-se indícios de que as palavras usadas em sala de aula pela professora foram sendo apropriadas pelo estudante em seu processo de reescrita, sendo esse movimento inerente ao processo de significação conceitual.

Observando-se a interação discursiva instituída, pode-se inferir que o símbolo DT encaminhado após a primeira reescrita levou $\mathrm{F}$ a explicar o fenômeno de solubilidade, não por meio do exemplo mencionado por ele (água e óleo), mas citando as moléculas de água e um composto iônico, quando usou termos como "interação íon-dipolo", destacando a importância da polaridade da água, como foi retratado no início de sua resposta: "as moléculas da água apresentam interações favoráveis com os compostos iônicos chamada de íon-dipolo". Isso explicita a falta da formação de um pensamento químico mais elaborado e/ou a limitação do uso de símbolo para o processo de orientação.

Pode-se depreender ainda que, devido ao símbolo DT, o estudante tenha aprimorado a explicação sobre a polaridade da molécula de água, passando a utilizar palavras como "carga nuclear efetiva" e "geometria molecular". Mas, ainda sim, em seu texto, F não conseguiu esclarecer a questão da solubilidade de compostos polares em água ou a não solubilidade, como no exemplo dado por ele sobre a água e o óleo. Por conta disso, a professora fez o seguinte comentário: "Amplie a explicação sobre a solubilidade ou não das substâncias moleculares em água" (Caderno de anotações, p. 31, 2012).

Já na terceira reescrita, o estudante F demonstrou um maior entendimento quanto à condição para o processo de solubilidade ao escrever que "[...] as interações entre as moléculas do solvente (água) e as do soluto é que são responsáveis pelo processo de solubilização" (Caderno de anotações, estudante F, p. 64, 2012). Por fim, considerando-se todo o processo de escrita e os diálogos estabelecidos, é possível afirmar que $\mathrm{F}$ procedeu ao processo de significação conceitual, pois todos os seus textos indicavam a importância das relações conceituais, mesmo retratando um pensamento por complexos ${ }^{6}$, o qual foi desencadeado até a terceira reescrita: "Os hidrocarbonetos são apolares, apresentam pouca solubilidade em água, assim a gasolina (mistura de octano e heptano), o óleo formam sistemas heterogêneos em água [...]" (caderno de anotações, estudante F, p. 63, 2012).

O estudante fez uso de exemplos e, a partir deles, efetuou as explicações, e esse é um caminho de apropriação e significação de acordo com Vigotski (2000). Ressalta-se que, na sala de aula, esse movimento é recorrente. Ou se parte de um exemplo para a explicação ou se dá a explicação e, em seguida, busca-se um exemplo.

No discurso escolar, é visível a preocupação quanto à relação do abstrato com o concreto, o que também foi possível verificar no primeiro comentário feito pela professora, no qual ela utilizou exemplos para nortear a escrita de F.

Apresentamos, em seguida, o diálogo mantido com o estudante G, que, em sua primeira escrita, ao responder à primeira questão encaminhada, assim escreveu:

a água é um solvente universal pois a água por ser uma molécula polar tem capacidade de dissolver moléculas polares, pois polar dissolve polar, e apolar dissolve apolar, num processo de solvatação. A hidratação de ions também é um fator que envolve a polaridade dessa molécula pois a força existente entre os ions são substituídos por força água e ions (Caderno de anotações, estudante G, p. 1, 2012). 
Em sua resposta, o estudante apenas considerou a propriedade que a água tem de ser um solvente universal. E a primeira orientação encaminhada pela professora consistiu num pedido de mais esclarecimentos sobre esse fenômeno: "Explique a afirmação de que a água por ser polar dissolve substâncias polares, pense em termos de forças interativas (interações interpartículas ${ }^{7}$ ) envolvidas no processo de dissolução" (Caderno de anotações, p. 4). Nessa orientação, a professora poderia ter explorado outras propriedades da água, as quais foram referidas na pergunta, mas não foram mencionadas pelo estudante. Todavia, o objetivo dela foi fazer com que ele argumentasse mais e avançasse na compreensão da descrição clássica e (re)producionista de que, por exemplo, "polar dissolve polar", explicitando os sentidos atribuídos por ele. Sendo assim, pode-se afirmar que a professora orientou o caminho, pela via da discussão de forças interativas.

O estudante, ao fazer a primeira reescrita, assim escreveu:

a polaridade de uma molécula refere-se às concentrações de cargas, numa nuvem eletrônica em volta da molécula. É possivel uma divisão em duas classes distintas: moléculas polares e apolares. Moléculas polares possuem maior concentração de carga negativa numa parte da nuvem e maior concentração positiva em outro extremo. Nas moléculas apolares, a carga eletrônica está uniformemente distribuída (Caderno de anotações, estudante G, p. 5, 2012)

Nesse caso, a orientação da professora consistiu na inserção do símbolo RI “(Resposta Incompleta - reler o comentário feito anteriormente ou reler a questão, a pergunta, o problema)". Examinando-se essa orientação, constatase uma lacuna, pois a atenção estava voltada para a primeira resposta. Por isso, ressalta-se que a professora poderia ter auxiliado $G$ sugerindo-lhe que explicasse a causa da polaridade das moléculas em termos de geometria molecular com o uso de expressões mais específicas, a exemplo de "a formação de dipolos na molécula". Contudo, isso não ocorreu, o que denota a importância de o professor estar mais atento às palavras e às explicações emitidas pelos estudantes e a necessidade de esse profissional se posicionar como mediador qualificado do processo interacional, para que suas orientações sejam, de fato, propulsoras de novos pensamentos.

Nesse contexto, destaca-se que a prática de inserir comentários explicativos para mediar a reescrita não foi nem é fácil, pois, além de ter requerido tempo da professora, trata-se de um processo que precisou ser apreendido por ela. Por exemplo, o posicionamento da profissional de não repassar a resposta pronta ao estudante ou de inserir um símbolo indicando a resposta certa ou errada exigiu-lhe uma postura pedagógica, diferente daquela adotada por pessoas que apresentam a resposta esperada ao aluno. Tomando essa iniciativa, a professora tinha como objetivo propiciar ao estudante a tomada de consciência acerca de suas limitações em relação a significados conceituais para poder avançar na reelaboração desses significados. Para tanto, foi preciso analisar que comentário seria capaz de conduzir o processo de produção do pensamento do estudante e de instigá-lo a ampliar e a reconstruir sua resposta, levando-se em conta que cada pessoa apresenta potencialidades cognitivas diferentes.

Por outro lado, ao estudante também foi requerido um posicionamento diferenciado. Ele precisaria retomar sua escrita, relê-la, posicionar-se frente a ela e 
buscar compreender a orientação dada pela professora. Enfim, tal prática exigiu o que Bakhtin (2006, p. 135) denomina como posicionamento responsivo, que, na enunciação, está vinculado à compreensão estabelecida no diálogo. Nas palavras do autor, compreender "é opor à palavra do locutor uma contrapalavra". É no processo de compreensão que pode ocorrer a significação, pois essa, diz Bakhtin (2006, p. 135), "só se realiza no processo de compreensão ativa e responsiva". Assim, nas interações discursivas favoráveis, é possível a significação conceitual, por exemplo.

O estudante $G$, em sua segunda reescrita (caderno de anotações, p. 17 e 18), apenas descreveu duas interações interpartículas: a dipolo-dipolo e as forças de London. Verificou-se uma simples cópia de livros didáticos, e, por isso, o texto não está reproduzido na integra. $\mathrm{O}$ aluno não fez qualquer relação com o questionamento inicial, qual seja o de a água atuar como solvente universal, e também não considerou as forças interpartículas específicas entre as moléculas da água e as demais substâncias/íons. É importante ressaltar, atentando-se especificamente para a interação discursiva instituída, que o termo "forças interpartículas", utilizado no texto da primeira orientação, levou $\mathrm{G}$ a escrever sobre duas forças intermoleculares - a dipolo-dipolo e a London -, sendo que uma é característica de moléculas polares e a outra, de moléculas apolares. Com essa descrição, o estudante não se preocupou em explicitar a definição clássica e recorrente no ensino - e apresentada por ele inicialmente - de que "polar dissolve polar e apolar dissolve apolar". Porém, ele descreveu cada uma das interações separadamente.

Tal fato mostra que o estudante não compreendeu a orientação encaminhada após a primeira escrita, a qual sugeria um raciocínio mais relacionado, que pensasse a causa de a água atuar como solvente universal e explicasse por que uma substância polar dissolve outra polar. Esta limitação, de não conseguir relacionar os conceitos, retrata apenas um início de apropriação conceitual. Ou seja, o estudante estava apenas se apropriando dos termos específicos da química, do diálogo apresentado em sala de aula. Em suas escritas, $G$ expôs definições isoladas, tentando explicar, por exemplo, os atributos das moléculas apolares e polares, e descrevendo somente as características de duas forças intermoleculares, sem conseguir relacioná-las.

Com base em Vigotski $(1993,2000)$, entende-se que, quando o estudante usa uma nova palavra, o processo de desenvolvimento conceitual está apenas se iniciando e que, ao se desenvolver internamente seu significado, com o uso da palavra em diferentes contextos, num processo mediado pelo professor, essa vai amadurecendo e ampliando os níveis de generalização. É válido ressaltar que Vigotski (2000) chama a atenção para a importância do elo entre os modos de formação conceitual e de pensamentos de origens diferentes: cotidiana e científica. Ambas ocorrem com movimentos de sentidos opostos, mas não seguem trajetórias paralelas. Uma não anula a outra. Ao contrário, elas podem, conforme Vigotski (2000), cruzar-se várias vezes, fundir-se, separar-se ou ainda andar lado a lado. O importante, como salienta o autor, é considerar que um processo de formação conceitual enriquece o outro. Sustentados por Vigotski, Cruz e Góes (2006, p. 35) afirmam que

os conceitos científicos, que no início de seu desenvolvimento são esquemáticos e desprovidos da riqueza advinda da experiência, ganham vitalidade e concretude em sua relação com os conceitos espontâneos. Por outro lado, as características do processo 
de construção de conceitos científicos transformam os espontâneos em termos de sistematicidade e reflexividade.

Nesse sentido, Bakhtin (2010, p. 263), defendendo o princípio dialógico da linguagem, destaca a relação mútua entre os gêneros primários e secundários do discurso. O autor argumenta que "os gêneros primários integram os secundários e adquirem um caráter especial, como, por exemplo, o de perder o vínculo com a realidade concreta". Os conceitos não são absorvidos prontos ou acabados, e sua formação consiste, conforme Vigotski (2000, p. 246), "num ato real e complexo de pensamento que não pode ser aprendido por meio de simples memorização". Assim, Bakhtin (2006, p. 109), ao se referir à língua materna, afirma "que os indivíduos não recebem a língua pronta para ser usada; eles penetram na corrente da comunicação verbal; ou melhor, somente quando mergulham nessa corrente é que sua consciência desperta e começa a operar". Desse modo, entende-se que é de forma análoga que os estudantes aprendem a nova linguagem da química e que a significação conceitual é possível somente mediante o uso dos conceitos científicos em espaços distintos, num processo sempre orientado pelo professor.

Ainda em relação à formação do pensamento por conceitos, Vigotski (2000) considera a necessidade da existência de três elementos psicológicos fundamentais, quais sejam: a possibilidade de se estabelecerem relações entre os conceitos ou no sistema de conceitos; a tomada de consciência sobre a própria atividade mental; e o surgimento de relações especiais, mais avançadas, que o indivíduo adquire com os objetos, o que lhe permite compreender melhor a essência deles.

Um conceito se relaciona com outro num sistema que implica uma nova estrutura de generalização. Nesse sistema, é instituída uma hierarquia de relações. Nas palavras de Vigotski (1993, p. 66), "um conceito de grau superior implica a existência de uma série de conceitos subordinados e pressupõe também uma hierarquia de conceitos com diversos níveis de generalidade". Nesse âmbito, o emprego do conceito se dá de maneira consciente. Assim, a análise da interação discursiva estabelecida mediante as orientações e as reorientações reporta para as especificidades do processo pedagógico, para as peculiaridades da formação do pensamento conceitual, demonstrando que essa não é simples nem imediata.

Seguindo o diálogo, visando qualificar a interação discursiva, em sua terceira orientação a professora solicitou ao estudante que ele aprimorasse sua resposta considerando as interações envolvidas na formação de soluções aquosas. O texto escrito na orientação foi o seguinte: "Você descreveu duas forças intermoleculares, pense agora na importância dessas para a formação de soluções aquosas, e retome a sua explicação inicial de que substância polar dissolve substância polar e substância apolar dissolve substância apolar" (Caderno de anotações, p. 18).

Nessa orientação, fez-se uso de um termo químico mais amplo, "soluções aquosas", o qual, por sua vez, implica o entendimento das interações interpartículas e da polaridade das substâncias. O objetivo da professora foi redirecionar a resposta do estudante $G$ para a primeira explicação dela e chamar a atenção do aluno para a importância das interações interpartículas na formação de soluções. Após esse comentário, na terceira reescrita o estudante escreveu: 
(iniciou a escrita representando a molécula de água, indicando os polos positivos e negativos, a geometria molecular e o ângulo de ligação) O oxigênio por ser mais eletronegativo atrai mais fortemente os elétrons que o bidrogênio, resultando num momento dipolar. A atração elétrica devido a esse dipolo aproxima as moléculas de água tornando mais difícil de separá-las e, por consequência, elevando o ponto de ebulição da água. Essa atração é conhecida como ligação de bidrogênio. A forma sólida da maioria das substâncias é mais densa que a fase líquida, assim um bloco de uma substância sólida pura afunda num recipiente cheio da mesma substância líquida pura. Mas ao contrário, um bloco de gelo comum flutua num recipiente de água por que a água sólida é menos densa que a água líquida (Caderno de anotações, estudante G, p. 25).

Nesse texto, percebe-se a ampliação de sentidos em alguns aspectos, indicando evolução conceitual. Apesar de não ter contemplado inteiramente a orientação da professora, $G$ avançou na explicação da polaridade da água em termos de momento dipolar resultante. Considerou, para tanto, o ângulo de ligação e a geometria molecular - por conta da representação que utilizou (desenho). Assim, o estudante passou da definição clássica de que "polar dissolve polar" para a utilização de conceitos relacionados, como "momento dipolar resultante" e "ângulo de ligação", remetendo ao entendimento da polaridade de uma molécula.

Pode-se compreender também que a interação discursiva realizada ainda não atingiu o âmago da dificuldade que o estudante apresenta: ele parece não relacionar polar/apolar como a expressão das forças interpartículas. Ele precisa ter consciência de que as forças elétricas interpartículas, responsáveis pela polaridade, provocam o fenômeno das dissoluções que estava em discussão. Isso quer dizer que a formação de um pensamento por conceitos, a capacidade de generalização sugere maior significação conceitual, a qual deve ser constantemente mediada no processo pedagógico.

De acordo com Bakhtin (2006), quando nos apropriamos de um gênero do discurso, conseguimos nos expressar com mais confiança no dia a dia. Como estamos inseridos nesse discurso, ele nos constitui, e, por isso, fazemos uso dele sem que haja qualquer problema. O estudante, ao se apropriar dos gêneros discursivos escolares, apesar de o caminho da apropriação ser inverso ao do discurso cotidiano, passou, por meio do processo de escrita e de reescrita orientadas, a utilizar, de maneira mais consciente, os termos da química para explicar determinado fenômeno, ou seja, ele foi significando o discurso escolar.

Outra constatação que se pode obter é que esse processo não é rápido e requer constante atenção e orientação qualificada do professor. $\mathrm{Na}$ análise das escritas dos estudantes F e G, pôde-se verificar que propiciar a composição de um texto com relações conceituais mais amplas foi muito difícil. As orientações que remetiam para a necessidade de um maior grau de generalização eram respondidas na forma de definições de alguns conceitos relacionados à temática, o que não significava uma efetiva evolução conceitual. À medida que o processo de reescrita acontecia, é que os estudantes avançavam nas relações conceituais, com a possibilidade da existência de uma evolução no processo de ensino, que não é compreendido como linear ou homogêneo, mas que demanda constantes interações discursivas, com o uso qualificado da LCE. Isso implica confrontos, desencontros de sentidos, mas objetiva um redimensionamento para a significação conceitual em química. 
Nesse âmbito, reforça-se a relevância da ampliação de espaços que possibilitem o uso da LCE, com atenção para a orientação pedagógica estabelecida no processo. É importante que o professor perceba as diferenças de significação conceitual dos estudantes para orientar o processo. Na prática de ensino vivenciada e analisada aqui, foi possível entender que o processo de significação conceitual requer um acompanhamento pedagógico interativo, qualificado e constante.

Destaca-se o fato de as orientações terem sido diferentes para cada aluno. Elas foram direcionadas pelas contrapalavras da professora frente a cada uma das respostas, num movimento dialógico, em que ela escrevia para o estudante, e esse, por sua vez, escrevia para ela.

No movimento de escrita e de reescrita analisado, ficou evidenciado que, além de questionar e de problematizar as respostas dos alunos, o professor deve, de fato, atuar como um potencial mediador no processo da reconstrução das respostas. Ou seja, é preciso que suas orientações produzam efeito nas possíveis Zonas de Desenvolvimento Proximais (ZDPs) dos estudantes, pois, conforme elucida Vigotski (2000, p. 113), para o aprendizado ser eficiente, ele deve possibilitar o uso das "funções que ainda não amadureceram, mas que estão em processos de maturação". Ou seja, o professor, através de sua orientação, pode possibilitar que o estudante desenvolva explicações mais elaboradas e, assim, avance na significação conceitual. Isso requer atenção e o uso de termos específicos para cada orientação.

É importante ressaltar que o posicionamento responsivo do estudante frente ao texto deve ser construído, e um caminho capaz de propiciar isso é a vivência da prática. No processo da interação discursiva aqui analisado, as limitações consistiram no fato de que, algumas vezes, os comentários feitos pela professora não indicavam aos alunos o caminho pensado por ela. Essa situação retrata a diferença entre o conhecimento do estudante e o do professor, e, mais uma vez, aponta a necessidade de o professor direcionar os diálogos em sala de aula.

\section{CONSIDERACְ̃̃ES FINAIS}

A investigação realizada sobre o processo de ensino nos permite afirmar que, ao fazer uso da palavra num movimento interativo de significação conceitual, o estudante amplia os sentidos, proporcionando a evolução do significado dos conceitos químicos, e, assim, seu pensamento conceitual em química começa a ser constituído. Diz Vigotski (2000, p. 398) que o "significado da palavra só é um fenômeno de pensamento na medida em que o pensamento está relacionado à palavra e nela materializado, e vice versa". Segundo o autor, não se pode ter qualquer pensamento sem a contribuição das palavras. O pensamento, continua ele, (2000, p. 412) "não se expressa, mas se realiza na palavra". Reforçam-se com isso os argumentos da importância de os estudantes fazerem uso da LCE na escrita de textos.

O processo vivenciado neste contexto permite-nos afirmar que não adianta apenas escrever a partir dos primeiros significados produzidos. É necessário adotar um posicionamento crítico reflexivo diante da escrita, num movimento que envolve leitura e reescrita. Mas esse posicionamento precisa ser aprendido. Por isso, é essencial que o professor atue como mediador por meio de desafios propostos ao 
estudante. E, considerando-se as especificidades da linguagem química, a orientação do professor torna-se ainda mais necessária, pois, com base em Vigotski (2000), entende-se que o aluno, por não usar a linguagem química, não amadureceu a palavra, isto é, essa ainda não tem significado suficiente e não é significativa para ele. Por isso, ele não a emprega em sua escrita, não consegue elaborar um pensamento utilizando-a, e, consequentemente, não escreve a partir dela.

A prática da reescrita orientada possibilitou aos estudantes aqui retratados retomarem seus textos e, com isso, conscientizarem-se acerca de suas limitações, aprimorando sua escrita e elevando a significação conceitual para novos níveis. Reitera-se, por fim, que um posicionamento crítico diante de um texto é possível à medida que o estudante se apropria do conhecimento e o significa. Daí a importância de o professor ser orientador, pois ele consegue, devido à sua formação anterior e à adquirida ao longo do processo de ensino, perceber incoerências ou limitações de significados químicos, os quais, para quem está sendo iniciado na química, podem passar despercebidos ou sem o devido entendimento.

Nessa direção, a prática pedagógica vivenciada e investigada reforçou a relevância do uso da linguagem química pelos estudantes. A análise dessa prática mostrou que os avanços na significação conceitual de estudantes foram possibilitados pela ajuda oferecida pelo professor na forma de orientações, o que lhe permitiu adentrar a ZDP dos alunos. Assim, reforça-se a importância de o professor, em sala de aula, fazer uso do discurso pedagógico, considerando-o constitutivo de um processo interativo sempre mediado pelo emprego intencional dos meios, pela utilização das palavras e dos conceitos próprios da química.

\section{NOTAS}

${ }^{1}$ Versão ampliada do escopo apresentado como comunicação oral no IX ENPEC, de 10 a 14 de novembro de 2013, em Águas de Lindoia, São Paulo. Cf. < http://www.nutes.ufrj.br/abrapec/ixenpec/>.

\footnotetext{
${ }^{2}$ Aulas de Química I, ministradas por um dos autores do artigo no decorrer de um semestre letivo de
} um curso de Licenciatura em Ciências de uma universidade federal do interior do Rio Grande do Sul.

${ }^{3}$ Os instrumentos pedagógicos foram: caderno de anotações; provas descritivas; reescrita orientada das provas e elaboração de mapas conceituais.

${ }^{4}$ Ofertado num Curso de Graduação em Ciências: Biologia, Física e Química Licenciatura de uma universidade federal do Interior do Rio Grande do Sul no ano de 2012. A universidade no período da pesquisa estava em fase de implantação.

5"A água, apesar de ser representada por uma fórmula molecular relativamente simples, composta apenas por dois elementos químicos, na proporção de 2:1, apresenta várias propriedades específicas e fundamentais para a vida. Entre elas, apresentar-se no estado líquido à temperatura ambiente, enquanto outras moléculas com massa molecular semelhante à da água - como, por exemplo, o metano $\left(\mathrm{CH}_{4}\right)$, a amônia $\left(\mathrm{NH}_{3}\right)$ e o sulfeto de hidrogênio $\left(\mathrm{H}_{2} \mathrm{~S}\right)$ - são gases nas mesmas condições. Também, a água apresenta menor densidade no estado sólido do que no estado líquido e, entre outras propriedades, é caracterizada como solvente universal. Explique, considerando a estrutura molecular da água, tais propriedades específicas.” 
${ }^{6}$ Pensamento característico de uma fase do pensamento infantil e que consiste na necessidade de relacionar as palavras com um objeto, com a sua representação concreta.

${ }^{7}$ Optamos por fazer uso desse termo, uma vez que, na maioria dos livros didáticos, as forças íon-dipolo, apesar das suas particularidades, são abordadas no mesmo contexto das forças intermoleculares. Não há uma preocupação em especificar a sua diferença em relação à natureza das partículas envolvidas, que é diferenciada numa interação dipolo-dipolo, por exemplo. Essas particularidades da linguagem química, as quais, muitas vezes, não são percebidas ou discutidas em aula, remetem novamente para a importância da apropriação e da significação conceitual em química.

\section{REFERÊNCIAS}

BAKHTIN, Mikhail M. (Volochinov). Marxismo e Filosofia da Linguagem. 12. ed. São Paulo: Hucitec, 2006. 201 p.

. Estética da Criação Verbal. Trad. Paulo Bezerra. 5.ed. São Paulo: WMF Martins Fontes, 2010, 476p.

CRUZ, M. N da; GÓES, M. C. R de. Sentido, Significado e Conceito: notas sobre as contribuições de Lev Vigotski. Pro-Posições, v. 17, n. 2, p. 31-45, maio/ago. 2006. Disponível em: <http://www.proposicoes. fe.unicamp.br/ proposicoes/textos/50_dossie_goes_mcr_etal.pdf >. Acesso em: out. 2012.

FONTANA, R. A. C. A Mediação pedagógica na sala de aula. 4. ed. Campinas, SP: Autores Associados, 2005.

MORAES, R.; GALIAZZI, M. C. Análise Textual Discursiva. 2. ed. ver. Ijuí: Ed. Unijuí, 2011. 224p. VIGOTSKI, L. S. Pensamento e linguagem. São Paulo: Martins Fontes, 1993.

. A construção do pensamento e da linguagem. Tradução de Paulo Bezerra. São Paulo: Martins Fontes, 2000. 296 p.

WENZEL, J. S.; MALDANER, O. A. A significação conceitual pela escrita e reescrita orientada em aulas de química. Química Nova, São Paulo, v. 37, n. 5, p. 908-914, 2014.

WENZEL, J. S. A significação conceitual em química em processo orientado de escrita e reescrita e a ressignificação da prática pedagógica. 2013, 230f. (Doutorado em Ensino de Ciências) - Universidade Regional do Noroeste do Estado do Rio Grande do Sul, Brasil, 2013.

Data de recebimento: $27 / 10 / 2014$

Data de aprovação: 20/06/2016

Data da versão final: 05/07/2016

\section{Contato:}

\section{Judite Scherer Wenzel}

Avenida Independência, $\mathrm{n}^{0} 713$, Centro

Salvador das Missões, RS - Brasil

CEP: $97.940-000$

juditescherer@uffs.edu.br 